\title{
New Metabolites from Endophytic Fungus Chaetomium globosum CDW7
}

\author{
Wei Yan ${ }^{1,2,+}$, Ling-Ling Cao ${ }^{1,2,+}$, Yang-Yang Zhang ${ }^{1,2}$, Ran Zhao ${ }^{1,2}$, Shuang-Shuang Zhao ${ }^{1,2}$, \\ Babar Khan ${ }^{1,2}$ and Yong-Hao Ye ${ }^{1,2, *}$ \\ 1 State \& Local Joint Engineering Research Center of Green Pesticide Invention and Application, \\ College of How Plant Protection, Nanjing Agricultural University, Nanjing 210095, China; \\ yanwei@njau.edu.cn (W.Y.); 2015202050@njau.edu.cn (L.-L.C.); zyy2857@163.com (Y.-Y.Z.); \\ 2017102130@njau.edu.cn (R.Z.); 2017202055@njau.edu.cn (S.-S.Z.); babarkhan.uaf@gmail.com (B.K.) \\ 2 Key Laboratory of Integrated Management of Crop Diseases and Pests, Ministry of Education, \\ Nanjing 210095, China \\ * Correspondence: yeyh@njau.edu.cn; Tel.: +86-25-8439-9753 \\ + These authors contributed equally to this paper.
}

Received: 10 October 2018; Accepted: 1 November 2018; Published: 4 November 2018

\begin{abstract}
Five metabolites including two new ones, prochaetoviridin A (1) and chaetoindolin A (2), were isolated from the endophytic fungus Chaetomium globosum CDW7. Compounds $\mathbf{1}$ and 2 were characterized as an isocoumarin and an indole alkaloid derivative, respectively, with their structures elucidated by comprehensive spectroscopic analyses including high-resolution electrospray ionization mass spectrometry (HR-ESI-MS), NMR, and circular dichroism (CD) comparison. Compounds 3-5 were identified as chaetoviridin A, chaetoglobosin $\mathrm{R}$, and chaetoglobosin $\mathrm{T}$, respectively. Chaetoviridin A (3) exhibited antifungal activity against Sclerotinia sclerotiorum with an $\mathrm{EC}_{50}$ value of $1.97 \mu \mathrm{g} / \mathrm{mL}$. In vivo test showed that 3 displayed a protective efficacy of $64.3 \%$ against rape Sclerotinia rot at the dosage of $200 \mu \mathrm{g} / \mathrm{mL}$, comparable to that of carbendazim $(69.2 \%)$.
\end{abstract}

Keywords: Chaetomium globosum; isocoumarin derivatives; indole alkaloid; antifungal activity

\section{Introduction}

Plant diseases caused by phytopathogenic fungi are one of the major problems contributing to crop loss. Over several decades, synthetic fungicides have been primarily developed to prevent and control plant diseases. However, the global trend appears to be shifting towards a reduced use of fungicides, and hence there is an urgent need for safer eco-friendly alternatives to treat plant diseases. Natural products, with their wide spectrum of bioactivities and environmentally friendly attributes, are the most promising source of lead molecules for agricultural chemicals [1,2].

Endophytic fungi are considered as prolific producers of natural products with structural and biological diversity [3,4]. Chaetomium globosum is a well-known member of the Chaetomiaceae family, which commonly resides on plants, soil, straw, and dung [5,6]. A large number of structurally diverse metabolites, such as chaetoglobosins, azaphilones, xanthones, and steroids, have been characterized from C. globosum species. These structures display a wide range of biological activities including anticancer, antimicrobial, immunosuppressive, and antioxidant [6-12].

Previously, we reported that C. globosum CDW7, an endophyte from Ginkgo biloba, exhibited strong inhibitory activity against plant pathogenic fungi in vitro. To explore the associated substance regarding its antifungal activities, flavipin, chaetoglobosins $\mathrm{A}$ and $\mathrm{D}$ were isolated using the bioassay-guided method [13-15]. During our ongoing search for new bioactive metabolites, one new isocoumarin derivative, prochaetoviridin A (1), and one new indole alkaloid, chaetoindolin A (2), 
together with chaetoviridin A (3), chaetoglobosins R and T (4 and 5) [16,17], were isolated from this fungus (Figure 1). Chaetoviridin A has been reported to be antifungal against some phytopathogens such as Rhizoctonia solani, Magnaporthe grisea and Pythium ultimum [18,19]. To the best of our knowledge, this is the first study of its activity against Sclerotinia sclerotiorum both in vitro and in vivo.

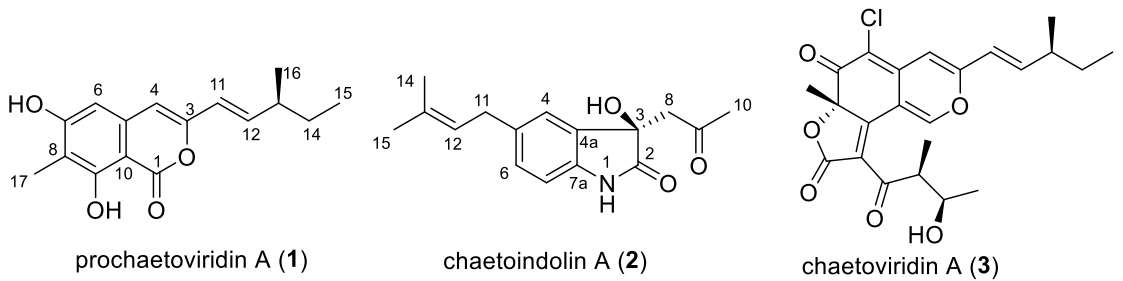

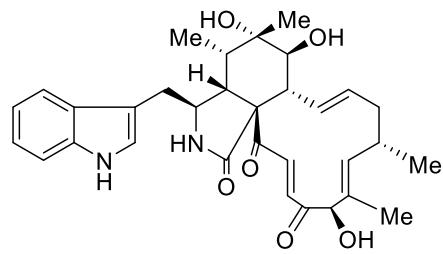

chaetoglobosin R (4)

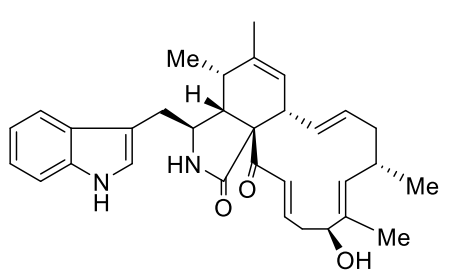

chaetoglobosin T (5)

Figure 1. Structures of compounds 1-5.

\section{Results and Discussion}

\subsection{Structure Elucidation}

Prochaetoviridin A (1) was obtained as a light-yellow powder. Its molecular formula, $\mathrm{C}_{16} \mathrm{H}_{18} \mathrm{O}_{4}$, with eight degrees of unsaturation, was determined by high-resolution electrospray ionization mass spectrometry (HR-ESI-MS) ( $m / z 297.1099\left([\mathrm{M}+\mathrm{Na}]^{+}\right.$; calcd. 297.1097). The ${ }^{1} \mathrm{H}$ NMR spectrum of 1 indicated the presence of three methyl groups (one singlet, one doublet, and one triplet), one methylene and one methine proton, one trans-olefinic group $(J=15.6 \mathrm{~Hz})$, two uncoupled olefinic or aromatic protons, and one hydroxyl group $\left(\delta_{\mathrm{H}} 11.42\right)$. The ${ }^{13} \mathrm{C}$ NMR spectrum revealed the existence of one lactone group $\left(\delta_{C}\right.$ 166.2) and one benzene ring (C-atoms ranging from $\delta_{C} 100.0$ to 161.3). The ${ }^{1} \mathrm{H}^{-1} \mathrm{H}$ COSY spectrum suggested the presence of a 3-methyl-1-pentenyl group. The HMBC correlations from H-6 $\left(\delta_{\mathrm{H}} 6.29\right)$ to C-8, C-4, and C-10, from H-17 $\left(\delta_{\mathrm{H}} 2.17\right)$ to C-7, C-8, and C-9, and from H-4 $\left(\delta_{\mathrm{H}} 6.15\right)$ to $\mathrm{C}-10$ constructed the core structure of 1 . The 3-methyl-1-pentenyl side chain was at the 3-position of the core ring as elucidated by the HMBC correlation from H-11 $\left(\delta_{\mathrm{H}} 5.95\right)$ to C-3 and C-4 (Table 1$)$. Thus, the whole structure was pieced together as shown in Figure 2. The stereochemistry of C-13 in the side chain is usually established by chromium trioxide oxidation [16,20], but we were unable do this experiment due to sample scarcity. Since compound 1 was closely related to the biosynthesis of chaetoviridin A (3), its absolute configuration was proposed as 13S, the same as the side chain of 3.

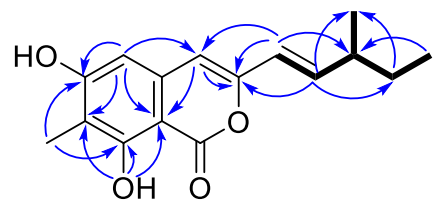

1

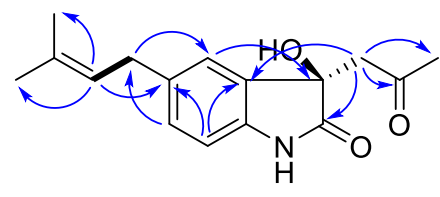

2

Figure 2. Key ${ }^{1} \mathrm{H}-{ }^{1} \mathrm{H}$ COSY (bold) and HMBC (solid arrows, blue) correlations of compounds $\mathbf{1}$ and 2. 
Table 1. NMR spectroscopic data of $\mathbf{1}$ in $\mathrm{CDCl}_{3}$.

\begin{tabular}{ccc}
\hline Position & $\boldsymbol{\delta}_{\mathbf{C}}$ & $\boldsymbol{\delta}_{\mathbf{H}}$ \\
\hline 1 & 166.2 & - \\
3 & 151.8 & - \\
4 & 104.3 & $6.15(\mathrm{~s})$ \\
5 & 136.8 & - \\
6 & 102.0 & $6.29(\mathrm{~s})$ \\
7 & 161.3 & - \\
8 & 110.4 & - \\
9 & 161.3 & - \\
$9-\mathrm{OH}$ & - & $11.42(\mathrm{~s})$ \\
10 & 100.0 & - \\
11 & 120.0 & $5.95(\mathrm{dd}, 0.8,15.6)$ \\
12 & 142.3 & $6.48(\mathrm{dd}, 8.1,15.6)$ \\
13 & 38.8 & $2.22(\mathrm{~m})$ \\
14 & 29.4 & $1.42(\mathrm{~m})$ \\
15 & 11.8 & $0.89(\mathrm{t}, 7.4)$ \\
16 & 19.7 & $1.07(\mathrm{~d}, 6.7)$ \\
17 & 7.8 & $2.17(\mathrm{~s})$ \\
\hline
\end{tabular}

Chaetoindolin A (2) was isolated as a colorless amorphous solid with the molecular formula $\mathrm{C}_{16} \mathrm{H}_{19} \mathrm{NO}_{3}$ as evidenced by HR-ESI-MS. The ${ }^{1} \mathrm{H}$ and ${ }^{13} \mathrm{C}$ spectra revealed three aromatic methines $\left(\mathrm{H}-4\left(\delta_{\mathrm{H}} 7.15, \mathrm{~s}\right), \mathrm{H}-6\left(\delta_{\mathrm{H}} 7.05, \mathrm{~d}, J=7.8 \mathrm{~Hz}\right)\right.$, and $\left.\mathrm{H}-7\left(\delta_{\mathrm{H}} 6.77, \mathrm{~d}, J=7.3 \mathrm{~Hz}\right)\right)$ and three quaternary aromatic carbons, suggesting the presence of a 1,2,4-trisubstituted benzene ring. This was verified by HMBC correlations from H-4 to C- 6 and C-7a, H-7 to C-4a and C-5, and H-6 to C-4 and C-7a. An isoprenyl unit was deduced by ${ }^{1} \mathrm{H}^{1}{ }^{1} \mathrm{H}$ COSY correlation between $\mathrm{H}-11\left(\delta_{\mathrm{H}} 3.29, \mathrm{~d}, J=7.3 \mathrm{~Hz}\right)$ and $\mathrm{H}-12\left(\delta_{\mathrm{H}} 5.26, \mathrm{~d}, J=7.3 \mathrm{~Hz}\right)$ and $\mathrm{HMBC}$ correlations from $\mathrm{H}-12$ to $\mathrm{C}-14$ and $\mathrm{C}-15$, and was indicated to be attached at C-5 mainly by the HMBC cross peaks for H-6/C-11 and H-11/C-4 (Table 2). Considering the molecular formula and the chemical shift of $C-3\left(\delta_{C} 74.8\right)$, a hydroxyl group was supposed to be at $\mathrm{C}-3$, indicating the presence of a 3-hydroxyoxindole ring. The HMBC correlations from $\mathrm{H}-8\left(\delta_{\mathrm{H}} 2.98\right.$ and $\left.\delta_{\mathrm{H}} 3.16\right)$ to $\mathrm{C}-10$ and $\mathrm{H}-10\left(\delta_{\mathrm{H}} 2.17\right)$ to $\mathrm{C}-8$ and $\mathrm{C}-9$ led to the elucidation of a 2-oxopropyl group, which was placed at C-3 by HMBC cross peaks for H-8/C-4a and H-8/C-2. The absolute configuration of $\mathbf{2}$ was determined by comparison of its circular dichroism (CD) spectrum with those of 3-hydroxyxoindole derivatives [21,22]. Compound $\mathbf{2}$ had a weak positive Cotton effect at $264 \mathrm{~nm}$, a negative one at $238 \mathrm{~nm}$, and a positive one at $215 \mathrm{~nm}$ (Figure 3), which resembled those of $(R)$-convolutamydine E [22]. Thus, we established the $3 R$ configuration of 2.

The structures of the other known compounds, chaetoviridin A (3), chaetoglobosin R (4), and chaetoglobosin $\mathrm{T}$ (5) were identified on the basis of their MS, ${ }^{1} \mathrm{H}$, and ${ }^{13} \mathrm{C}$ NMR data by comparison with the data reported previously in the literature $[16,17]$.

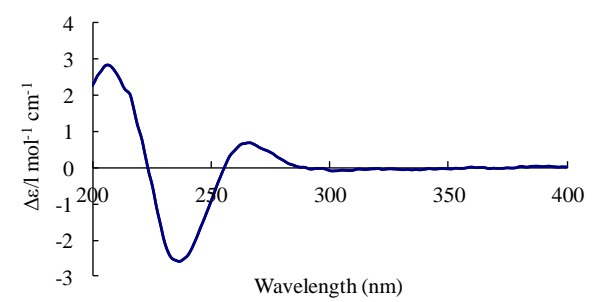

Figure 3. Circular dichroism (CD) spectrum of compound 2. 
Table 2. NMR spectroscopic data of 2 in $\mathrm{CDCl}_{3}$.

\begin{tabular}{ccc}
\hline Position & $\boldsymbol{\delta}_{\mathbf{C}}$ & $\boldsymbol{\delta}_{\mathbf{H}}$ \\
\hline 2 & 178.4 & - \\
3 & 74.8 & - \\
$4 \mathrm{a}$ & 130.6 & - \\
4 & 124.7 & $7.15(\mathrm{~s})$ \\
5 & 137.4 & - \\
6 & 130.1 & $7.05(\mathrm{~d}, 7.8)$ \\
7 & 110.7 & $6.77(\mathrm{~d}, 7.8)$ \\
$7 \mathrm{a}$ & 138.6 & - \\
8 & 48.8 & $2.98(\mathrm{~d}, 17.1)$ \\
9 & 207.9 & $3.16(\mathrm{~d}, 17.1)$ \\
10 & 31.6 & - \\
11 & 34.1 & $2.17(\mathrm{~s})$ \\
12 & 123.5 & $3.29(\mathrm{~d}, 7.3)$ \\
13 & 133.0 & $5.26(\mathrm{t}, 7.3)$ \\
14 & 25.9 & - \\
15 & 17.9 & $1.74(\mathrm{~s})$ \\
\hline
\end{tabular}

\subsection{Biological Activity}

All isolated compounds were evaluated for their antifungal activities against pathogenic fungi at the concentration of $20 \mu \mathrm{g} / \mathrm{mL}$. Prochaetoviridin A (1) showed moderate antifungal activity with inhibition rates ranging from $13.7 \%$ to $39.0 \%$. Chaetoviridin A (3) was active against S. sclerotiorum, Botrytis cinerea, Fusarium graminearum, Phytophthora capsici and F. moniliforme with inhibition rates of $97.8 \%, 69.1 \%, 77.0 \%, 60.7 \%$, and $59.2 \%$, respectively. Other compounds $(2,4$ and 5$)$ displayed no obvious effect (Table 3). The $\mathrm{EC}_{50}$ value of 3 against $S$. sclerotiorum was further determined as $1.97 \mu \mathrm{g} / \mathrm{mL}$, compared to that of positive control (carbendazim, $0.17 \mu \mathrm{g} / \mathrm{mL}$ ). In vivo test revealed that 3 could successfully inhibit disease development in S. sclerotiorum-infected rape with $45.2 \%$ and $64.3 \%$ protective efficiency and dosages of 100 and $200 \mu \mathrm{g} / \mathrm{mL}$, respectively, which is comparable to those of carbendazim (44.6\% and 69.2\%) (Figure 4, Table 4).

Table 3. Inhibition rates (\%) of compounds against five phytopathogenic fungi.

\begin{tabular}{cccccc}
\hline Pathogenic Fungi & $\mathbf{1}$ & $\mathbf{2}$ & $\mathbf{3}$ & $\mathbf{4}$ & $\mathbf{5}$ \\
\hline S. sclerotiorum & 39.0 & 21.5 & 97.8 & 3.5 & 0.5 \\
B. cinerea & 18.8 & 0 & 69.1 & 9.9 & 20.5 \\
F. graminearum & 24.0 & 7.9 & 77.0 & 1.6 & 2.6 \\
P. capsici & 13.7 & 8.5 & 60.7 & 6.6 & 8.6 \\
F. moniliforme & 31.6 & 6.3 & 59.2 & 12.5 & 15.7 \\
\hline
\end{tabular}

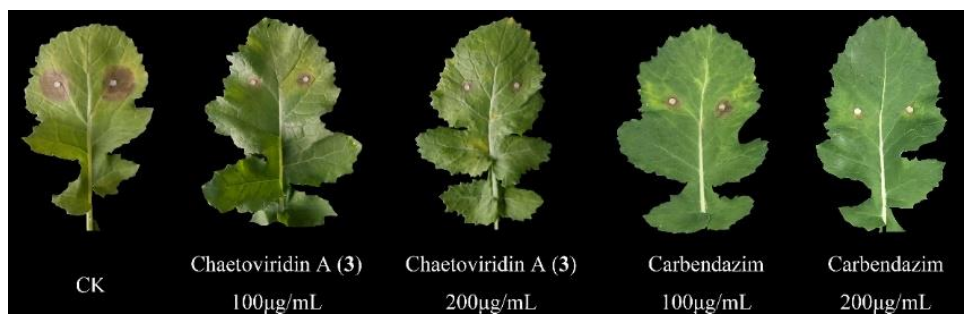

Figure 4. Effects of chaetoviridin A (3) against S. sclerotiorum-infected cole leaves. CK, control check (5\% DMSO without compounds). 
Table 4. In vivo efficacy of compounds on cole leaves infected by S. sclerotiorum ${ }^{1 .}$

\begin{tabular}{cccc}
\hline Compound & Treatment $(\mu \mathbf{g} / \mathbf{m L})$ & Diameter Lesion Length $(\mathbf{m m})$ & Protective Efficacy $(\mathbf{\%})$ \\
\hline $\mathbf{3}$ & 200 & $12.5 \pm 0.9$ & 64.3 \\
& 100 & $16.5 \pm 1.2$ & 45.2 \\
Carbendazim $^{2}$ & 200 & $11.5 \pm 0.6$ & 69.2 \\
& 100 & $16.6 \pm 0.5$ & 44.6 \\
Negative control & - & $26.0 \pm 1.4$ & - \\
\hline \multicolumn{4}{c}{}
\end{tabular}

\section{Materials and Methods}

\subsection{General Experimental Procedures}

The UV spectra were obtained from a Hitachi U-3000 spectrophotometer (Hitachi, Tokyo, Japan). Optical rotations were measured on a Rudolph Autopol III automatic polarimeter (Rudolph Research Analytical, Hackettstown, NJ, USA). CD spectra were acquired on a JASCO-810 spectropolarimeter (JASCO, Easton, MD, USA). NMR spectra were obtained using a Bruker DRX-600 NMR spectrometer (Bruker, Fällanden, Switzerland) at room temperature with TMS (tetramethylsilane) or solvent signals as calibration. High-resolution electrospray ionization mass spectrometry (HR-ESI-MS) results were recorded on an Agilent 6210 TOF LC-MS spectrometer (Agilent Technologies, Santa Clara, CA, USA). Silica gel (200-300 mesh) for column chromatography (CC) was purchased from Qingdao Marine Chemical Factory, Qingdao, China. Sephadex LH-20 was produced by Pharmacia Biotech, Uppsala, Sweden. Semi-preparative HPLC purification was carried out on a Kromasil 100-5-C18 column (5 $\mu \mathrm{M}$, $250 \times 10 \mathrm{~mm}$, AkzoNobel, Shanghai, China). All chemicals used in the study were of analytical or HPLC grade.

\subsection{The Source of Strains}

C. globosum CDW7 and all tested plant pathogens were supplied and stored by the Laboratory of Natural Products and Pesticide Chemistry, Nanjing Agricultural University. The strains were cultivated in potato dextrose agar (PDA) at $25{ }^{\circ} \mathrm{C}$ after retrieval from the storage tube.

\subsection{Fermentation, Extraction, and Isolation}

Strain CDW7 was incubated on PDA at $25^{\circ} \mathrm{C}$ for 5 days. Then, the mycelial agar plugs were transferred from the edge of the cultures to $1000 \mathrm{~mL}$ Erlenmeyer flasks containing $400 \mathrm{~mL}$ of Czapek's medium ( $30 \mathrm{~g}$ sucrose, $1 \mathrm{~g}$ yeast extract, $3 \mathrm{~g} \mathrm{NaNO}_{3}, 0.5 \mathrm{~g} \mathrm{MgSO}_{4} \cdot 7 \mathrm{H}_{2} \mathrm{O}, 10 \mathrm{mg} \mathrm{FeSO}_{4} \cdot 7 \mathrm{H}_{2} \mathrm{O}, 1 \mathrm{~g}$ $\mathrm{K}_{2} \mathrm{HPO}_{4}, 0.5 \mathrm{~g} \mathrm{KCl}$, in a final volume of $1 \mathrm{~L}$ water), which was continuously shaken (150 rpm) for 10 days. The broth culture $(40 \mathrm{~L})$ was filtered through muslin cloth and extracted with ethyl acetate (EtOAc) three times to give the crude extract $(60 \mathrm{~g})$. The crude extract was subjected to silica gel column chromatography eluted stepwise with $\mathrm{CH}_{2} \mathrm{Cl}_{2}-\mathrm{MeOH}$ (100:0, 100:1, 100:2, 100:4, 100:8, and 0:100) as the mobile phase to afford six fractions, Fr1-Fr6. Fr2 was fractionated by CC over silica gel (EtOAc/petroleum, $v / v, 100: 0-0: 100$ ) to give five fractions (Fr2.1-Fr2.5). Fr2.3 was further separated on a Sephadex LH-20 column eluted with $\mathrm{MeOH}$ to yield compound $\mathbf{1}(1.8 \mathrm{mg})$. Fr4 was subjected to a Sephadex LH-20 column eluted with $\mathrm{MeOH}$ several times and separated by semi-preparative HPLC $\left(\mathrm{MeOH} / \mathrm{H}_{2} \mathrm{O}, 75: 25\right)$ to give $2\left(2.4 \mathrm{mg}, \mathrm{R}_{\mathrm{t}}=17.5 \mathrm{~min}\right)$. Fr2.2 was separated by CC Sephadex LH-20 and purified by semi-preparative HPLC $\left(\mathrm{MeOH} / \mathrm{H}_{2} \mathrm{O}, 85: 15\right)$ to give $3\left(27 \mathrm{mg}, \mathrm{R}_{\mathrm{t}}=25.6 \mathrm{~min}\right)$. Fr4.4 was subjected to silica gel and Sephadex LH-20 CC to afford $4(5.5 \mathrm{mg})$ and $5(7.2 \mathrm{mg})$.

Prochaetoviridin A (1): light yellow powder, $[\alpha]_{\mathrm{D}}^{20} 2.5(\mathrm{c} 0.25, \mathrm{MeOH}) ; \mathrm{UV}(\mathrm{MeOH}) \lambda \max (\log \varepsilon) 252$ (2.9), $261(3.1) \mathrm{nm} ; \mathrm{CD}(\mathrm{MeOH}) \lambda \max (\Delta \varepsilon) 228(+0.7), 253(+1.7), 259(+1.4)$; HR-ESI-MS $m / z$ 297.1099 $[\mathrm{M}+\mathrm{Na}]^{+}$(cacld. $\left.\mathrm{C}_{16} \mathrm{H}_{18} \mathrm{O}_{4} \mathrm{Na}, 297.1097\right) .{ }^{1} \mathrm{H}$ and ${ }^{13} \mathrm{C}$ NMR spectroscopic data, see Table 1. 
Chaetoindolin $A$ (2): colorless amorphous solid, $[\alpha]_{\mathrm{D}}^{20} 1.8(\mathrm{c} 0.50, \mathrm{MeOH}) ; \mathrm{UV}(\mathrm{MeOH}) \lambda \max (\log \varepsilon) 202$ (2.0), 259 (0.2) nm; CD (MeOH) $\lambda \max (\Delta \varepsilon) 215$ (+4.3), 238 (-3.2), 264 (+1.1); HR-ESI-MS $m / z$ 296.1254 $[\mathrm{M}+\mathrm{Na}]^{+}$(cacld. $\left.\mathrm{C}_{16} \mathrm{H}_{19} \mathrm{NO}_{3} \mathrm{Na}, 296.1257\right) .{ }^{1} \mathrm{H}$ and ${ }^{13} \mathrm{C}$ NMR spectroscopic data, see Table 2.

\subsection{Antifungal Assays}

The antifungal tests were conducted according to the protocols described in previous literature [15].

\section{Conclusions}

Rape Sclerotinia rot (RSR) caused by S. sclerotiorum seriously affects the production and quality of rape seed in China and the other regions of the world [23]. The present work suggests that chaetoviridin A (3) showed promising bioactivity against $S$. sclerotiorum. Thus, natural products-especially those from C. globosum species-remain a diverse source of bioactive lead molecules for both agricultural and pharmaceutical uses.

Supplementary Materials: The following are available online, NMR spectra of compounds $\mathbf{1}$ and 2.

Author Contributions: Conceived the study: W.Y., L.-L.C. and Y.-H.Y. Designed the study: W.Y. and Y.-H.Y. Performed the experiments: W.Y., L.-L.C., Y.-Y.Z. and R.Z. Contributed reagents/materials/analysis tools: S.-S.Z. and B.K. Analyzed data and wrote the paper: W.Y. and Y.-H.Y.

Funding: This research was funded by National Key Research and Development Program of China (2017YFD0201100), the National Natural Science Foundation of China (21602109 and 31572043) and the Fundamental Research Funds for the Central Universities (KYZ201612).

Conflicts of Interest: The authors declare no conflict of interest.

\section{References}

1. Zhang, G.Z.; Zhang, Y.H.; Qin, J.C.; Qu, X.Y.; Liu, J.L.; Li, X.; Pan, H.Y. Antifungal metabolites produced by Chaetomium globosum No.04, an endophytic fungus isolated from Ginkgo biloba. Indian J. Microbiol. 2013, 53, 175-180. [CrossRef] [PubMed]

2. Cantrell, C.L.; Dayan, F.E.; Duke, S.O. Natural products as sources for new pesticides. J. Nat. Prod. 2012, 75, 1231-1242. [CrossRef] [PubMed]

3. Fatima, N.; Muhammad, S.A.; Khan, I.; Qazi, M.A.; Shahzadi, I.; Mumtaz, A.; Hashmi, M.A.; Khan, A.K.; Ismail, T. Chaetomium endophytes: A repository of pharmacologically active metabolites. Acta Physiol. Plant. 2016, 38, 136-153. [CrossRef]

4. Yan, W.; Li, S.J.; Guo, Z.K.; Zhang, W.J.; Wei, W.; Tan, R.X.; Jiao, R.H. New p-terphenyls from the endophytic fungus Aspergillus sp. YXf3. Bioorg. Med. Chem. Lett. 2017, 27, 51-54. [CrossRef] [PubMed]

5. Li, L.M.; Zou, Q.; Li, G.Y. Chromones from an ascomycete, Chaetomium aureus. Chin. Chem. Lett. 2010, 21, 1203-1205. [CrossRef]

6. Li, H.; Liao, Z.B.; Tang, D.; Han, W.B.; Zhang, Q.; Gao, J.M. Polyketides from two Chaetomium species and their biological functions. J. Antibiot. 2018, 7, 677-681. [CrossRef] [PubMed]

7. Chen, C.M.; Wang, J.; Zhu, H.C.; Wang, J.P.; Xue, Y.B.; Wei, G.Z.; Guo, Y.; Tan, D.D.; Zhang, J.W.; Yin, C.P.; et al. Chaephilones A and B, two new azaphilone derivatives isolated from Chaetomium globosum. Chem. Biodivers. 2016, 13, 422-426. [CrossRef] [PubMed]

8. Chen, C.M.; Tong, Q.Y.; Zhu, H.C.; Tan, D.D.; Zhang, J.W.; Xue, Y.B.; Yao, G.M.; Luo, Z.W.; Wang, J.P.; Wang, Y.Y.; et al. Nine new cytochalasan alkaloids from Chaetomium globosum TW1-1 (Ascomycota, Sordariales). Sci. Rep. 2016, 6, 18711. [CrossRef] [PubMed]

9. Youn, U.J.; Sripisut, T.; Park, E.J.; Kondratyuk, T.P.; Fatima, N.; Simmons, C.J.; Wall, M.M.; Sun, D.; Pezzuto, J.M.; Chang, L.C. Determination of the absolute configuration of chaetoviridins and other bioactive azaphilones from the endophytic fungus Chaetomium globosum. Bioorg. Med. Chem. Lett. 2015, 25, 4719-4723. [CrossRef] [PubMed] 
10. Qin, J.C.; Gao, J.M.; Zhang, Y.M.; Yang, S.X.; Bai, M.S.; Ma, Y.T.; Laatsch, H. Polyhydroxylated steroids from an endophytic fungus, Chaetomium globosum ZY-22 isolated from Ginkgo biloba. Steroids 2009, 74, 786-790. [CrossRef] [PubMed]

11. Ge, H.M.; Yan, W.; Guo, Z.K.; Luo, Q.; Feng, R.; Zang, L.Y.; Shen, Y.; Jiao, R.H.; Xu, Q.; Tan, R.X. Precursor-directed fungal generation of novel halogenated chaetoglobosins with more preferable immunosuppressive action. Chem. Commun. 2011, 47, 2321-2323. [CrossRef] [PubMed]

12. Yan, W.; Ge, H.M.; Wang, G.; Jiang, N.; Mei, Y.N.; Jiang, R.; Li, S.J.; Chen, C.J.; Jiao, R.H.; Xu, Q.; et al. Pictet-Spengler reaction-based biosynthetic machinery in fungi. Proc. Natl. Acad. Sci. USA 2014, 111, 18138-18143. [CrossRef] [PubMed]

13. Xiao, Y.; Li, H.X.; Li, C.; Wang, J.X.; Li, J.; Wang, M.H.; Ye, Y.H. Antifungal screening of endophytic fungi from Ginkgo biloba for discovery of potent anti-phytopathogenic fungicides. FEMS Microbiol. Lett. 2013, 2, 130-136. [CrossRef] [PubMed]

14. Ye, Y.H.; Xiao, Y.; Ma, L.; Li, H.X.; Xie, Z.L.; Wang, M.H.; Ma, H.T.; Tang, H.W.; Liu, J.Y. Flavipin in Chaetomium globosum CDW7, an endophytic fungus from Ginkgo biloba, contributes to antioxidant activity. Appl. Microbiol. Biotechnol. 2013, 16, 7131-7139. [CrossRef] [PubMed]

15. Zhao, S.S.; Zhang, Y.Y.; Yan, W.; Cao, L.L.; Xiao, Y.; Ye, Y.H. Chaetomium globosum CDW7, a potential biological control strain and its antifungal metabolites. FEMS Microbiol. Lett. 2017, 3, fnw287. [CrossRef] [PubMed]

16. Takahashi, M.; Koyama, K.; Natori, S. Four new azaphilones from Chaetomium globosum var. flavor-viridae. Chem. Pharm. Bull. 1990, 38, 625-628. [CrossRef]

17. Jiao, W.X.; Feng, Y.J.; Blunt, J.W.; Cole, A.L.J.; Munro, M.H.G. Chaetoglobosins Q, R, and T, three further new metabolites from Chaetomium globosum. J. Nat. Prod. 2004, 10, 1722-1725. [CrossRef] [PubMed]

18. Awad, N.E.; Kassem, H.A.; Hamed, M.A.; El-Naggar, M.A.A.; El-Feky, A.M.M. Bioassays guided isolation of compounds from Chaetomium globosum. J. Mycol. Med. 2014, 24, e35-e42. [CrossRef] [PubMed]

19. Park, J.H.; Choi, G.J.; Jang, K.S.; Lim, H.K.; Kim, H.T.; Cho, K.Y.; Kim, J.C. Antifungal activity against plant pathogenic fungi of chaetoviridins isolated from Chaetomium globosum. FEMS Microbiol. Lett. 2005, 252, 309-313. [CrossRef] [PubMed]

20. Wang, W.Y.; Liao, Y.Y.; Chen, R.X.; Hou, Y.P.; Ke, W.Q.; Zhang, B.B.; Gao, M.L.; Shao, Z.Z.; Chen, J.M.; Li, F. Chlorinated azaphilone pigments with antimicrobial and cytotoxic activities isolated from the deep sea derived fungus Chaetomium sp. NA-S01-R1. Mar. Drugs 2018, 16, 61. [CrossRef] [PubMed]

21. Kamano, Y.; Zhang, H.P.; Ichihara, Y.; Kizu, H.; Komiyama, K.; Pettit, G.R. Convolutamydine-A, a novel bioactive hydroxyoxindole alkaloid from marine bryozoan Amathia-convoluta. Tetrahedron Lett. 1995, 36, 2783-2784. [CrossRef]

22. Nakamura, T.; Shirokawa, S.I.; Hosokawa, S.; Nakazaki, A.; Kobayashi, S. Enantioselective total synthesis of convolutamydines B and E. Org. Lett. 2006, 8, 677-679. [CrossRef] [PubMed]

23. Wang, Y.; Hou, Y.P.; Chen, C.J.; Zhou, M.G. Detection of resistance in Sclerotinia sclerotiorum to carbendazim and dimethachlon in Jiangsu Province of China. Australas. Plant Pathol. 2014, 43, 307-312. [CrossRef]

Sample Availability: Samples of the compounds 1-5 are available from the authors.

(C) 2018 by the authors. Licensee MDPI, Basel, Switzerland. This article is an open access article distributed under the terms and conditions of the Creative Commons Attribution (CC BY) license (http:/ / creativecommons.org/licenses/by/4.0/). 